tion for Archæology, Philips Academy, Andover, Massachusetts, U.S.A.)

With regard to future procedure, it was decided that all carbon-dating laboratories should check by a common standard and that this should be the oxalic acid standard of the U.S. Bureau of Standards. It was agreed that a value of 95 per cent of this standard activity could be taken as the agreed radiocarbon activity for organic material (but not shells) originating in A.D. 1950. This decision should remove many of the minor difficulties caused by the different laboratories having individual standards of contemporary activity on which to base their calculations of age, and it is hoped that either the next or the next but one date-list of every laboratory will be based upon this agreed standard, which will take care of the industrial carbon and hydrogen-bomb effects upon recent samples. It was at the same time recognized that the carbonate sample provided by Heidelberg would be a further check of importance; that laboratory has undertaken the co-ordination of all inter-laboratory calibration measurements.

It was agreed to defer decision on a carbon-13 standard, pending exact absolute determinations to be made in the Lamont Laboratories.

It was agreed to use the methods of presentation of bibliography now employed in the Radiocarbon Supplement and in Quaternaria : the conference also recommended that now dating stations should adopt as their index letters the most distinct and simple combination possible, avoiding those that have already been used even by stations not at present producing dates.

While there was no agreement as to whether dates ought preferably to be expressed as B.P. (before the present), or B.C. (and A.D.), there was considerable sympathy for the view that dates primarily relevant to archæology should be given in the B.C./A.D. scale, even where the date B.P. had also been given.

Members of the conference had the concentration of lecture room attendance broken by visits to Prof. de Vries's laboratory, to the great peat bog and moraine region south of Groningen and to the dramatic areas of reclamation where carbon-dating is assisting the Geological Survey to provide fundamental knowledge of the stratigraphy of coastal deposits.

The thanks of all participants are due to all our Dutch hosts, to the Rektor Magnificus of the University of Groningen, to the Royal Dutch Shell Company, to the Chief Engineer and Director of the Rijks Waterstaat, and above all to the primary organizers of the conference.

H. GoDwIN

${ }^{1}$ Godwin, H., Nature, 174, 868 (1954).

${ }^{2}$ Levi, H., Nature, 176, 727 (1955).

sohnson, F., Arnold, J. R., and Flint, R. F., Science, 125, 240 (1957). - Vries, Hi. de, Proc. Kon. Ned. Akad. van Wetenschappen, B, 61 (2), 1 (1958).

'Vries, H1. de, Vries, A. E. de, and Harris, A., Science, 128, 472 (1958).

\title{
ENZYMES IN THE FOOD INDUSTRY
}

$\mathrm{T}$ HE Committee of the Food Group of the Society of Chemical Industry has an established reputation for organizing symposia on subjects of vital importance and with a wide range of interest to food scientists and technologists. The most recent, held on October 1-2, dealing with enzymes associated with the manufacture, storage and distribution of food, attracted an audience which taxed the capacity of the hall of the Royal Society of Medicine in which it was held. The organizers very wisely decided to limit the scope of the contributions and to divide them roughly into two groups: one dealing with the production of enzymes and their use in manufactured foods and the other with the activity, both useful and deleterious, of naturally occurring enzymes in foods.

Dr. Malcolm Dixon opened the symposium with a paper, giving in his own characteristic way the necessary background information on the types of reactions which may be catalysed by enzymes, and such of their properties as would have $a$ bearing on the matters discussed by later speakers. The value of such an introduction to a symposiuna covering a broad field of biochemistry cannot be too highly stressed when it is appreciated that the audience was composed mainly of persons connected with the food manufacturing and processing industries, specialists maybe in rather limited fields, who frequently find it hard to keep abreast of fundamental developments.

The remainder of the first day was given over to papers dealing with fungal amylase, invertase, rennin, glucose-oxidase, the pectin-degrading enzymes and proteinases from plants and micro-organisms. The main interest in fungal amylase and invertase was in the methods adopted to secure conditions of culture of the selected organism so that high yields of high-purity enzyme are possible on a commercial scale. The discussion on the papers not unexpectedly centred around the newer applications of enzymes by the food industry and in particular the use of amylase in bread-making, the application of such proteinases as papain, bromelin (from pineapple) and ficin (from figs) to meat with the view of increasing its tenderness, and the recent availability of glucose oxidase as an oxygen scavenger in packaged foods.

The proceedings of the first day having presented the enzymes in a favourable light, as procossing aids in a variety of food products, the second day, devoted to "Innate Enzymes: Their Action and Control", revealed the reverse side of the medal and showed enzymes in a less co-operative mood. This was not unexpected : Dr. Dixon, in his introductory remarks, had already pointed out that foods are the product of enzyme action in the living plant or animal and are metabolized after consumption by enzyme action in the body of the consumer, stressing the fact that in the living cell the urge of the enzyme processes is towards synthesis and that enzyme changes in foods, which can be regarded as post-mortem changes, may well be deteriorative in character. It is, however, sometimes difficult to draw the line; the enzymic ripening of fruit leads progressively into the deteriorative changes of over-ripening. Other cases are more specific: papers presented during the day dealt with onzymic deterioration in colour (blackening of potatoes by polyphenolase), in flavour ('soapiness' in coconut and palm kernel oil products due to liberation of free fatty acids by lipase action) and in nutritive value (oxidation of ascorbic acid and of vitamin A precursors in plant tissues). 
The problem of control is a formidable one. Cold storage merely delays but does not prevent enzymic deterioration, since enzyme reactions, like all other chemical reactions, are slowed but not stopped by lowering of temperature. Other standard methods, such as the addition of inhibitors or competitive sub. strates, are by no means universally applicable. Probably the most commonly used procedure is that of heat inactivation ('blanching'), but this can lead to unwanted structural changes in fruits and vegetables. At present there is no simple and universal solution.

It must be said that on one point the arrangement of the symposium was open to critical attack, namely, the lack of time available for free discussion. It is in this discussion that the value of a symposium such as this largely resides, both for the audience and for the contributors themselves. Arrangements had been made for the discussions to be opened by appropriate authorities and these authorities presented what virtually amounted to additional contributions, com- parable in weight and importance to those of the main contributors. On this account, the unscripted discussion was seriously restricted, particularly at the final session, and a number of potential questions had to remain unasked and unanswered. This was undoubtedly a loss and one can but ask that the point should be borne in mind when future symposia are being planned.

It is, however, pleasant to record that the symposium went with a swing to the end and was closed by the clock : there was no noticeable whittling away of the audience as special interests were disposed of. In its lighter moments the meeting considered future possibilities; these included 'tailored' enzymes for specified purposes and the application of enzymes to the restoration of flavour in over-cooked cabbage. It was also pointed out that one speaker had coined a new word-the verb "to enzyme". The purists may refuse to accept this innovation, but we must all accept the importance of the process it describes.

\section{BIOCHEMICAL RESEARCH IN INDIA}

\section{GOLDEN JUBILEE SYMPOSIUM}

\begin{abstract}
A SERIES of symposia was organized by the Department of Biochemistry, Fermentation and Pharmacology Laboratories of the Indian Institute of Science, as part of the celebrations of the golden jubilee of the Institute, during August 28-30, and was attended by more than two hundred scientists, including fifty delegates representing important centres of biochemical research in the country. The subjects covered were "Biology and Biochemistry of Micro-organisms", "Enzymes" and "Vitamins".

The symposia were inaugurated by Dr. S. Bhagavantam, the director of the Indian Institute of Science, and the first day of the session was presided over by Major-General S. L. Bhatia, who spoke on the "Progress of Physiology and Biochemistry in India". Prof. P. S. Sarma, who presided over the proceedings of the socond day, outlined the contributions in enzyme chemistry made by the late Prof. K. V. Giri (see Nature, 182, 1201 ; 1958). Dr. V. N. Patwardhan, who took the chair on the third and final day of the symposium, gave an address on the mode of action of vitamin $\mathrm{D}$ on which he and his group have been working for the past two decades. $\mathrm{He}$ and his collaborators have adduced experimental evidence to show that vitamin $\mathrm{D}$ acts presumably by promoting the synthesis of citric acid in the epiphyseal cartilage. Dr. V. Subrahmanyan, director of the Central Food Tochnological Research Institute, Mysore, who was professor of biochemistry in the Indian Institute of Science from 1931 until 1949, reviewed the work done in the department during his regime. He gave a bricf account of the development of the Bangalore process of composting, the elucidation of the principles of sewage purification, the preparation of a material from paddy husk for defluorinating fluoride-containing waters and the preparation of insulin and other hormones from slaughter-house material and vegetable 'milk' from soya bean. Prof. M. Sreenivasaya, who was one of the pioneers in enzyme chemistry during the early years of the Biochemistry Department, described the elegant method developed by him for the study
\end{abstract}

of enzymes both by the ultra-micro- as well as by micro-dilatometric methods.

Sixty-nine original research papers were presented at the symposia, and only a selection can be mentioned here.

M. G. Bhat, of the Indian Institute of Science, read a paper on the nutrition and metabolism of Pseudomonas convexa var. hippuricum representing the work done by her in collaboration with Drs. T. Ramakrishnan and J. V. Bhat. Dotailed investigations with regard to the nutritional requirements and metabolic pathways of this organism, which was isolated from soil using the enrichment culture technique, were outlined and a new pathway of benzoate breakdown by the bacteria involving salicylate, a mechanism different from the classical scheme of the metabolism of the aromatic ring, described. M. K. Subramanyam (Indian Institute of Science) gave a résumé of his studies on the eytology of yoast, which included the demonstration of the presence of a nucleus and a vacuole as well as the occurrence of nuclear and vacuolar membranes in the yeast cell. He also pointed out the general similarity of the structures of yeast and plant nuclei.

M. Chakravorty and D. P. Burma, of the Bose Institute, Calcutta, presented a paper on "Microbial Synthesis of Protein in Relation to the Biogenesis of Nucleic Acids". Using phosphorus-32 and sulphur-35, they have shown that, in the resting cell of Azotobacter vinelandii, conditions under which nucleic acid synthesis is inhibited lead to a docrease in protein synthesis. On the contrary, it was found that the incorporation of phosphorus-32 into the nucleic acid continued in an uninterrupted manner even when protein synthesis was inhibited. P. S. Sarma and co-workers, of the University Biochemical Laboratory, Madras, working on metal requirements of nicotinamide deaminases, have investigated the inhibition by metal-chelating agents of nicotinamidedeamidating systems in cell-free extracts of micro. organisms and the soluble fractions of pigeon liver. A study of the reversal of the inhibition, produced 